\title{
KOAH ve Overlap Sendromlu Hastalarda Kardiyopulmoner Egzersiz Testinin Değerlendirilmesi*
}

\author{
ArZu ERTEM CENGIZ1 ${ }^{1}$, Funda COŞKUN², Ahmet URSAVAŞ ${ }^{2}$ \\ 1 Bursa Yüksek İhtisas Hastanesi, Göğüs Hastalıkları Kliniği, Bursa. \\ 2 Bursa Uludağ Üniversitesi Tıp Fakültesi, Göğüs Hastalıkları Anabilim Dalı, Bursa.
}

\section{ÖZET}

Kronik Obstrüktif Akciğer Hastalığı (KOAH) sistemik inflamasyon ile seyreden bir hastalıktır ve sistemik inflamasyon KOAH’ta morbidite ve mortalitenin ana nedenidir. OSAS ve KOAH birlikteliği yani Overlap Sendromu (OS) toplumda \% 1 sıklı̆̆ında görülmektedir. Bu iki hastalığın birlikteliğinde sistemik inflamasyon şiddeti daha da artmaktadır. Bu nedenle de OS'lı hastalarda morbidite ve mortalite daha fazla oranda görülmektedir. Bu çalışmanın amacı KOAH ve OS'li hastalarda kardiyopulmoner egzersiz testleri arasında anlamlı farklılık olup olmadığını saptamaktı. Çalışmamızda 18 hastaya Kardiyopulmoner Egzersiz Testi (KPET) yapılmıştır. Test yapılan hastaların 12'si KOAH'lı ve 6'sı OS'lu idi. Çalışmaya alınan hastalara Vmax Encore, USA cihazı kullanılarak semptom sinırlı incremental KPET uygulandı. KPET sonucu maksimum oksijen tüketimi (VO2max ml/kg/min) KOAH'lı grupta 15,5 $\pm 6,4$, OS'lı grupta 12,4 6 saptandı. Bu açıdan anlamlı fark yoktu $(\mathrm{P}>0,05)$. Karbondioksit üretimi ( $\mathrm{VCO} 2 \mathrm{~L} / \mathrm{min})$ açısıdan da iki grup arasında anlamlı fark saptanmadı ( $>00,05)$. Maksimum

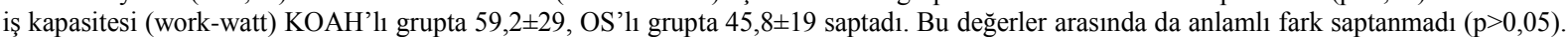
Hastaların maksimum kalp hızı dakikada KOAH'lı grupta 120 21 , OS'lı grupta $116 \pm 18$ olarak saptandı. Oksijen pulse değeri (ml/atım) ve maksimum kalp hızı açısından İki grup karş̧laştırmasında anlamlı fark yoktu ( $\mathrm{p}>0,05)$.Maksimum ventilasyon oranı (VEmax-L/dk) KOAH'lı grupta 43 \pm 13 , OS'lı grupta 36,6 $\pm 9,2$ olarak saptadı. İki grup arasında anlamı fark saptanmadı $(\mathrm{p}>0,05)$. Endtidal $\mathrm{CO} 2$ değeri ve Endtidal O2 değeri açısında KOAH'lı ve OS'lı grup karşılaştıııldığında anlamlı fark saptanmadı $(\mathrm{p}>0,05)$. Solunum katsayısı yani RQ oranı

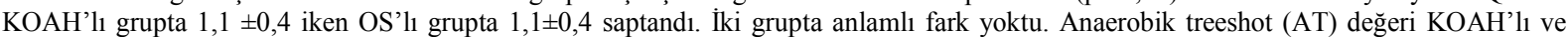
OS'lı grupta benzerdi. Bu değerler arasında da istatistiksel anlamlı fark saptanmadı ( $>00,05)$. Sonuç olarak değerlendirildiğinde KOAH ve OS'lu hastalarda KPET değerlerini normal popülasyona göre düşük saptamakla birlikte iki hastalık arasında anlamlı farklılık saptamadık.

Anahtar Kelimeler: KOAH. Overlap Sendromu. KPET.

Comparison of Cardiopulmonary Exercise Tests for Patients with COPD and Overlap Syndrome

\begin{abstract}
Chronic Obstructive Pulmonary Disease (COPD) is a disease that progresses through inflammation and the main reason for morbidity in COPD is this inflammation. The rate of appearance of OS (Overlap Syndrome) and COPD together is \%1 in the general public. Systemic inflammation increases the severity even more when the two diseases appear together. This is why the morbidity and mortality rates are higher with patients diagnosed with OS. The purpose of this study is to find out whether there is a significant difference between the cardiopulmonary exercise test results for patients with the COPD and Overlap Syndrome (OS). 18 patients were subjected to Cardiopulmonary Exercise Tests (CPET) within the scope of the study. 12 of the patients were diagnosed with COPD and 6 of them with OS. A symptomlimited incremental CPET was performed using a Vmax Encore, USA device. Informed consent was obtained from all subjects. The results of the KPET revealed that the maximum oxygen consumption $\left(\mathrm{VO}_{2 \max } \mathrm{ml} / \mathrm{kg} / \mathrm{min}\right)$ in the group of patients with COPD was $15,5 \pm 6,4$, and $12,4 \pm 6$ in the group with OS. There was no significant difference in that sense ( $>>0,05)$. There was also no significant difference in carbon dioxide outturn between the two groups $\left(\mathrm{VCO}_{2} \mathrm{~L} / \mathrm{min}\right)(\mathrm{p}>0,05)$. The maximum work-watt in the group of patients with COPD was 59,2 \pm 29 , and $45,8 \pm 19$ in the group with OS. There also was no significant difference between these results $(\mathrm{p}>0,05)$. The maximum throb of the group of patients diagnosed with COPD was $120 \pm 21$, and $116 \pm 18$ in the group with OS. The comparison of Oxygen pulse value (ml/Pulse) and maximum throb did not show any significant difference either $(\mathrm{p}>0,05)$. The maximum ventilation rate $\left(\mathrm{VE}_{\max }-\mathrm{L} / \mathrm{min}\right)$ in the group of patients with COPD was $43 \pm 13$, and 36,6 $\pm 9,2$ in the group with OS. No significant difference was found between the two groups. (p>0,05). End-tidal $\mathrm{CO}_{2}$ values and end-tidal $\mathrm{O}_{2}$ values did not show any significant difference either. When compared $(\mathrm{p}>0,05)$. The respiratory quotient RQ in the group with COPD was $1,1 \pm 0,4$ whereas in the group with OS the value was $1,1 \pm 0,4$. No significant difference. The anaerobic thresold (AT) values in both groups were similar. No statistically significant difference was found between these two values either. $(p>0,05)$. Although the CPET values of patients diagnosed with COPD and OSD were below the general population, there were no significant differences between the two diseases.
\end{abstract}

Key Words: COPD. Overlap Syndrome. CPET.

Geliş Tarihi: 13 Eylül 2019

Kabul Tarihi: 10 Ekim 2019

* IUPS Kongresi'nde poster bildiri olarak sunulmuştur (21-26 Temmuz 2013, Birmingham, Ingiltere)
Dr. Funda COSKUN

Bursa Uludağ Üniversitesi Tıp Fakültesi,

Göğüs Hastalıkları Anabilim Dalı, Bursa.

Tel.: 5332500099

E-posta: fundacoskun@gmail.com 
Overlap Sendromu (OS) Kronik Obstrüktif Akciğer Hastalığı (KOAH) olan hastalara Obstrüktif Uyku Apne Sendromunun (OSAS) eşlik etmesidir. Toplumda yapılan çalışmaların verilere göre yetişkinlerin yaklaşık \%1'de görülür. KOAH hastalarında uyku apne prevalansı artmıştır ${ }^{1,2}$. OS olan hastalarda nokturnal hipoksi daha sık meydana gelmektedir, pulmoner hipertansiyon gelişmesine daha yatkındırlar, ölüm riski diğer $\mathrm{KOAH}$ hastalarına göre daha fazladır ${ }^{3,4}$. KOAH sirasinda meydana gelen inflamasyon ve bunun üzerine eklenen OSAS sinerjistik etki göstermektedir, dolayısıyla bu hastalarda kardiyovasküler hastalik ve ateroskleroz gelişme riski artmıştır ${ }^{3}$.

Kardiyopulmoner Egzersiz Testi (KPET) kardiyak, solunumsal ve kas fonksiyonlarını değrlendirmek için kullanılan bir stres test yöntemidir. Sistemik inflamasyonun varlığı KOAH olgularında KPET sonuçlarında bozulmalara yol açmaktadır. KOAH'ta egzersiz kısıtlamasına neden olan en sik semptom dispnedir. $\mathrm{KOAH}$ olgularında solunum güçlügüünün olmasıyla ek karbondioksit üretimi olur ve düşük iş yükünde laktik asit düzeyinde belirgin artış gözlemlenir. Bütün bunların sonucu olarak egzersiz sürdürme kapasitesi oldukça düşüktür ve $\mathrm{VO}_{2}$ değeri düşük bulunur. Benzer yaş ve cinsiyet grubundaki bireylere göre, aynı iş yükünde harcanan oksijen tüketimi artmıştır. Bununla ilişkili olarak düşük iş hızlarında artmış laktik asit gözlemlenebilir.

OSAS hastalarında ise KPET'de olan değișiklikler tartışmalıdır. Bu hastalar genellikle obezdirler. Obesite herhangi bir akciğer hastalığı bulunmasa dahi FRC'de ve ERV'de azalmaya yol açar. Bu azalma sonucunda ise solunum işi için harcanacak enerji artış gösterir.

Overlap sendromlu olgularda egzersiz sirasindaki metabolik değişiklikler ile ilgili yeterli veri bulunmamaktadır. Bu çalışmanın amacı bu hasta grubunda metabolizmadaki değişiklikleri saptayabilmektir.

\section{Gereç ve Yöntem}

Aralık 2011 ve Temmuz 2012 tarihleri arasında Göğüs Hastalıkları polikliniğine başvuran KOAH'lı 30 hasta çalışmaya alındı. Çalışmaya alınan tüm hastalara aydınlatılmış onam belgesi imzalatıldı. Çalışma öncesinde Tıbbi Araştırmalar Etik Kurulundan 15 Haziran 2010 tarih ve 2010-13/2 No'lu karar ile onay alınmıştır.

Çalışma Dışı Bırakılma Kriterleri:

- Gündüz oksijen değeri < 60 mmHg olması

- Hastanın bilinen OSAS tanıs1 olmas1

- Solunum yetmezliği tanısı ile oksijen tedavisi ve/veya BPAP tedavisi alıyor olması

- Alevlenme döneminde olması
Hastalardan öncelikle gündüz hipoksisini dışlamak için istirahatte kan gazı alındı. Arter kan gazı örnekleri radial arterden alındı ve alınmadan önce her hastaya Allen testi uygulandı. Arter kan gazı tetkikinde hastanemizde bulunan hazır kan gazı enjektörü kullanıldı. Hastalardan $2 \mathrm{ml}$ arteriyel kan alındı. Bu kan 30 dakika içerisinde hastanemizde bulunan NOVA biomedical Stat Profile Critical Care Xpress kan gazı ölçüm cihazı ile çalışıldı. İşlem sonrası hastalara radial artere 5 dakika kompresyon uygulandi.

Daha sonra hastalar kliniğimiz uyku laboratuarında polisomnogafi yapılmak üzere bir gece yatırıldı. Hastalara Compumedics uyku izleme sistemi (Compumedics e-series: Compumedics Melbourne, Australia) kullanılarak tüm gece PSG yapıldı. PSG yapılan hastalar yaklaşık saat 20.30'da uyku laboratuarında bulundular ve yaklaşık saat 23.00 de PSG başlatıldı. Uyku monitörizasyonu için 16 kanallı bilgisayarlı ve video kayıtlı PSG cihazı kullanıldı. PSG kaydı iki elektroensefalografi (EEG) kayd1 C3A2 ve O2/A1), iki elektrookülogram (EOG) kaydı, bir submental elektromyogram (EMG) kaydı ve elektrokardiyogram (EKG) kaydı ile oluşturuldu. Solunum monitörizasyonu oronazal hava akım ölçümü (oronazal termistör ile), pulseoksimetre ile hemoglobin oksijen desatürayonu $\left(\mathrm{SaO}_{2}\right.$, parmak oksimetri yolu ile), göğüs duvarı (pletismografi ile), karın solunum hareketleri ve vücut pozisyonunun takibi ile yapıldı

Uyku evrelemesi AASM kriterlerine uygun yapıldı. Uyku süresince nazal akımı düzenli ve dikkatli olarak analiz edildi. Apne, hava akımında en az 10 sn durma epizodunun izlenmesi olarak tanımlandı. Hipopne de termistör sinyal amplitütünde en az 10 sn süren ve en az \%30 azalma ile birlikte oksijen saturasyonunda \%4 düşme olarak belirlendi. Uykuda görülen apne ve hipopne sayıları toplamının saat olarak uyku süresine ile AHİ elde edildi. AHİ>5 olan olgular OSAS tanisı aldilar.

Çalışmaya alınan hastalardan 18 tanesine Göğüs Hastalıkları Solunum Fonksiyon Testleri laboratuvarında aynı cihazda ve aynı saatlerde testler uygulandı. Masterscreen Body Plestismografi, USA cihazında hastaların $\mathrm{FEV}_{1}$, FVC, $\mathrm{PI}_{\max }, \mathrm{PE}_{\max }$, DLCO, TLC, RV ölçümleri yapıldı.

Hastaların fizik durumları değerlendirilerek toplam 18 hastaya kardiyopulmoner egzersiz testi uygulandi. Kardiyopulmoner egzersiz testleri $\mathrm{V}_{\max }$ Encore USA, sistemi kullanılarak bisiklet ergometresinde yapıldı. Hastalara incrementel tipte maksimum egzersiz testi (10-20 W/dak) protokolu uyguland1. $\mathrm{VO}_{2 \max }, \mathrm{VE}_{\max }$, $\mathrm{VCO}_{2 \max } \mathrm{vb}$ parametreler ölçülerek değerlendirildi.

\section{İstatistiksel analiz}

Verinin istatistiksel analizi SPSS 20.0 istatistik paket programında yapılmıştır. Verinin normal dağılım gösterip göstermediği Shapiro-Wilk testi ile incelenmiştir. Normal dağılmayan veri için iki grup karşılaş- 


\section{KOAH ve Overlap Sendromunda KPET}

tırmasında Mann-Whitney U testi kullanılmıştır. Değişkenler arasındaki ilişkiler Pearson korelasyon katsayısı ile incelenmiştir. Kategorik verinin incelenmesinde Pearson Ki-kare testi ve Fisher'in Kesin Ki-kare testi kullanılmıştır. Anlamlılık düzeyi $\mathrm{p}<0.05$ olarak belirlenmiştir.

\section{Bulgular}

KPET sonucu maksimum oksijen tüketimi $\left(\mathrm{VO}_{2 \max }\right.$ $\mathrm{ml} / \mathrm{kg} / \mathrm{min}$ ) KOAH'l grupta $15,5 \pm 6,4$, OS'l grupta $12,4 \pm 6$ saptand1. $\mathrm{Bu}$ açıdan anlamlı fark yoktu (p>0,05). Karbondioksit üretimi $\left(\mathrm{VCO}_{2} \mathrm{~L} / \mathrm{min}\right)$ açısıdan da iki grup arasında anlamlı fark saptanmadı ( $>00,05)$. Maksimum iş kapasitesi (work-watt) KOAH'l 1 grupta 59,2 \pm 29 , OS'l1 grupta $45,8 \pm 19$ saptad. $\mathrm{Bu}$ değerler arasında da anlamlı fark saptanmadı $(\mathrm{p}>0,05)$. Hastaların maksimum kalp hızı dakikada KOAH'l grupta $120 \pm 21$, OS'lı grupta $116 \pm 18$ olarak saptand. Oksijen pulse değeri (ml/atım) ve maksimum kalp hızı açısından İki grup karşılaştırmasında anlamlı fark yoktu ( $>00,05)$. Maksimum ventilasyon oran1 ( $\left.\mathrm{VE}_{\max }-\mathrm{L} / \mathrm{dk}\right)$ KOAH'l 1 grupta $43 \pm 13$; OS'l grupta $36,6 \pm 9,2$ olarak saptadı. İki grup arasında anlamı fark saptanmadı $(\mathrm{p}>0,05)$. End-tidal $\mathrm{CO}_{2}$ değeri ve End-tidal $\mathrm{O}_{2}$ değeri açısında $\mathrm{KOAH}$ 'ı ve OS'l grup karşılaştırıldığında anlamlı fark saptanmad ( $>0,05)$. Solunum katsayısı yani RQ oranı KOAH'l grupta $1,1 \pm 0,4$ iken OS'lı grupta $1,1 \pm 0,4$ saptand1. İki grupta anlamlı fark yoktu. Anaerobik treeshot (AT) değeri KOAH'lı ve OS'lı grupta benzerdi. Bu değerler arasında da istatistiksel anlamlı fark saptanmadı $(\mathrm{p}>0,05)$. Hastaların KPET verilerinin ayrıntılı karşılaştırılması Tablo I'de özetlenmiştir.

Tablo I. Olguların KPET değerleri

\begin{tabular}{|c|c|c|c|}
\hline & $\begin{array}{l}\text { KOAH } \\
(n: 12)\end{array}$ & $\begin{array}{l}\text { OS } \\
(n: 6)\end{array}$ & \multirow{11}{*}{$p>0,05$} \\
\hline $\mathrm{VO}_{2 \max }(\mathrm{ml} / \mathrm{kg} / \mathrm{dk})$ & $15,5 \pm 6,4$ & $12,4 \pm 6$ & \\
\hline $\mathrm{VCO}_{2}(\mathrm{~L} / \mathrm{dk})$ & $0,87 \pm 0,3$ & $0,69 \pm 0,3$ & \\
\hline Maksimum iş (Watt) & $59,2 \pm 29$ & $45,8 \pm 19$ & \\
\hline Maximum kalp hızı (dk) & $120 \pm 21$ & $116 \pm 18$ & \\
\hline $\mathrm{O}_{2}$ pulse (ml/atım) & $9,3 \pm 4,1$ & $7,9 \pm 4,2$ & \\
\hline$V_{\max }(\mathrm{L} / \mathrm{dk})$ & $43 \pm 13$ & $36,6 \pm 9,2$ & \\
\hline End-tidal $\mathrm{CO}_{2}$ & $37,5 \pm 10,3$ & $32,1 \pm 10$ & \\
\hline End-tidal $\mathrm{O}_{2}$ & $94,8 \pm 8,6$ & $91,3 \pm 6$ & \\
\hline $\mathrm{RQ}$ & $1,1 \pm 0,4$ & $1,1 \pm 0,4$ & \\
\hline AT & $0,7 \pm 0,2$ & $0,7 \pm 0,2$ & \\
\hline
\end{tabular}

\section{Tartışma}

Kardiyopulmoner egzersiz testleri (KPET) kardiyak, pulmoner ve kasların değerlendirilmesinde önemli bir test aracıdır. Dispnenin ayırıcı tanısında kullanılmakla birlikte egzersiz intoleransının asıl sebebinin ne oldu$\breve{g u}$ konusunda geniş kapsamlı bilgi ancak KPET yap1larak elde edilebilir. Kronik akciğer hastalarında en önemli semptomlar nefes darlığı ve bozulmuş fonksiyonel kapasitedir. Egzersiz sırasındaki fiziksel kondisyon yetersizliği ve bozulmuş egzersiz performans1na bağlı olarak semptomlar ortaya çıkmaktadır. Kronik obstrüktif akciğer hastalığında patofizyolojik belirleyici ekspiratuvar akım kısıtlanmasıdır. Egzersiz sırasında akım kısıtlanması olan olgularda ventilasyonun artışı sonucunda hava hapsi oluşur ve dinamik hiperinflasyona yol açar.

KOAH'ta kardiyopulmoner parametrelerde sıklıkla görülen değişiklikler birçok yayında saptanmıştır ${ }^{5-7}$. KPET'de $\mathrm{VO}_{2 \text { pik }}$ ve $\mathrm{VE}_{\text {pik }}$ azalır. $\mathrm{VE}_{\text {pik }}$ azalması mekanik kısıtlanma ile açıklanabilir. Solunum rezervi azalır. $\mathrm{VE}_{\text {pik }} / \mathrm{MVV}$ artar. VE/ $/ \mathrm{VCO}_{2}$ artar. Böylelikle ventilatuvar etkinlik azalır. $\mathrm{P}(\mathrm{A}-\mathrm{a}) \mathrm{O}_{2}$ ve $\mathrm{P}(\mathrm{a}-\mathrm{ET}) \mathrm{CO}_{2}$ artar. $\mathrm{PaO}_{2}$ ve $\mathrm{PCO}_{2}$ de değişken cevap alınır. Anaerobik eşik düşük iş yükünde iken gözlenir. KOAH olgularında egzersiz kapasitesinin azalması sonucunda nefes darlığı ve bacak ağrısı gelişir. KOAH'da oluşan patofizyolojik değişimler sonrasında ventilasyon / perfüzyon dengesi bozulur. Vd/Vt artar. $\mathrm{PaO}_{2}$ ve $\mathrm{pH}$ azalır. $\mathrm{Bu}$ da beraberinde ventilatuvar ihtiyaç artışına sebep olur. Diğer taraftan solunum işinin artması ile birlikte hava akımı kısıtlanır ve elastik recoil azalır. Bunun sonucu olarak da ventilatuvar kapasite azalır. Hem ventilatuvar kapasitesinin azalması hem de ventilatuar ihtiyacın artışı egzersiz kısıtlanmasına ve nefes darl1ğına sebep olur. Artan ventilatuar ihtiyacın karşılanması için tidal volum artırılır ve ekspirasyon zamanı azaltılır. Bu durum ise hava hapsine ve dinamik hiperinflasyona neden olur. KOAH olguları hızlı ve yüzeyel soluyarak ventilatuvar ihtiyacı karşılamaya çalışırlar. Ekspirasyon sonu akciğer volümü (EELV) artırılarak ekspirasyon akım hızı artırılmaya çalışılır. Dinamik hiperinflasyon ekspiratuvar hava-akım kısıtlanmasının derecesi, istirahatteki hiperinflasyon derecesi, maksimum ekspiryum akım-volüm eğrisi şekli, VE ve Ti/Ttot oranı ile ilişkilidir. Dinamik hiperinflasyon inspiratuar kas uzunluğunu ve dayanıklılı̆̆ını azaltır. Solunum işini ve oksijen tüketimini ise artırır. Orta ve ileri KOAH'ta egzersizde ventilatuvar kısitlanmayı solunum rezervinin azalması gösterir. VEmax/MVV oranı \%100'e yaklaşır veya geçer ${ }^{8-13}$.

İleri KOAH olgularında kardiyak kısıtlanma egzersiz testinde saptanır. Şiddetli dinamik hiperinflasyon nedeniyle venöz dönüş azalır, sağ ventrikül ön yükü azalır. İntratorasik basınç değişiklikleri nedeniyle sol ventrikül ard yükünde artma görülür. KOAH'a bağlı olarak pulmoner arter basincında ve pulmoner vasküler dirençte artma sağ ventrikül ard yükünü artırır ve ejeksiyon fraksiyonunu azaltır.

Arteryel kan gazları egzersiz sırasında değerlendirildiğinde KOAH hastalarının parsiyel oksijen basıncı değişkendir. $\mathrm{PO}_{2}$ artabilir, azalabilir veya normal kalır. 
Difüzyon defektleri, şantlar ve ventilasyon/perfüzyon dengesizliği sonucunda parsiyel oksijen basıncında değişiklikler görülür. $\mathrm{PCO}_{2}$ artabilir veya stabil kalır. $\mathrm{Vd} / \mathrm{Vt}$ oranındaki artış $\mathrm{PCO}_{2}$ basıncında değişikliklere neden olur. Ayrica KOAH'lı olgularda solunum kaslarının fonksiyonel yetersizliği de egzersiz kapasitesini sinırlamaktadır. Diyaframda ve solunum kaslarındaki güçsüzlük ve yorgunluk egzersiz kapasitesinin sınırlanma nedenlerindendir. KOAH olgularında kas kitlesi azalır, lif tipleri değişir, kas gücü ve dayanıklılığı azalır. Egzersiz sırasında dinamik hiperinflasyon, ventilasyonda artma ve akciğer ve göğüs duvar kompliansında azalma nedeniyle inspiratuar kas basıncı artar.

OSAS hastalarında gündüz aşırı uykululuk hali, azalmış günlük aktivite ve doku hipoksisi sonucunda kas fonksiyonlarında bozulma ve egzersiz toleransında azalma meydana gelmektedir. Peppard ve Young vücut alışkanlığından bağımsız olarak OSAS şiddetiyle egzersiz toleransındaki azalma arasında ilişki göstermişlerdir ${ }^{14}$. Lin ve ark. yaptıkları çalışmada orta ve ağır şiddete 20 OSAS hastasını OSAS olmayan kontrol grubuyla karşılaștırmışlardır ${ }^{15}$. OSAS'lı grupta maksimum $\mathrm{VO}_{2}$ 'de ve iş yükünde kontrol grubuna göre azalma saptamışlardır. Aynı zamanda OSAS'lı grupta anaerobik eşik değerinde (AT) ve oksijen nabzında kontrol grubuna göre azalma bulunmuştur. Lin ve ark.'ları OSAS'lı grupta anormal KPET sonuçlarının olduğunu ve bu sonuçların kardiyak hastalıklara, pulmoner vasküler hastalıklara ve büyük olasılıkla egzersiz intoleransına yol açtığı görüşüne yer vermişlerdir. Nanas ve ark. yaptıkları çalışmada 21 OSAS' ${ }_{1}$ erkek hasta ile 10 sağlıklı erişkin erkek hastayı karşılaştırmışlardır. OSAS'lı grupta egzersiz kapasitesinde düşme, kalp hızı iyileşmesinde azalmayı anlamlı olarak saptamışlar, OSAS'lı hastalarda oksijen kinetiğinde kötüleşme olduğunu ifade etmişlerdir ${ }^{16}$.

Bizim çalışmamızda 12 kişi KOAH ve 6 kişi OSAS ve KOAH olan olgularda KPET yapılarak veriler değerlendirilmiştir. KOAH'ın egzersiz testlerindeki parametrelerde bozulmalar yaptığ olgulardaki KPET değişiklikleri daha önce araştırılmamıştır. Çalışmamızda bu iki grup arasında anlamlı farklılık izlenmemiştir. Kontrol grubumuz olmadığ için KOAH'a bağlı değişikleri de göstermemiz mümkün olmamıştır. Bununla birlikte KOAH olgularında KPET'de görülen $\mathrm{VO}_{2 \text { pik }}$ ve $\mathrm{VE}_{\text {pik }}$ azalması saptanmıştır. Semptom sınırlı maksimal test yapılan olgularda egzersiz süresinin ve yük miktarının beklenen değerlere göre daha düşük olduğu da gözlenmiştir.

Sonuç olarak egzersiz parametrelerinde KOAH hastalığında görülen değişiklikler dışında OS ek bir deği- şiklik saptanamamıştır. Olgu sayının az oluşu, sağlıklı kontrol grubunun olmayışı bu çalışmanın kısıtlılıkların1 göstermektedir.

\section{Kaynaklar}

1. McNicholas WT. Chronic obstructive pulmonary disease and obstructive sleep apnea: Overlaps in pathophysiology, systemic inflammation, and cardiovascular disease. Am J Respir Crit Care Med. 2009;180:692-700

2. Chaouat A, Weitzenblum E, Krieger J, Ifoundza T, Oswald M, Kessler R. Association of chronic obstructive pulmonary disease and sleep apnea syndrome. Am J Respir Crit Care Med. 1995;151:82-86.

3. Lee R, McNicholas WT. Obstructive sleep apnea in chronic obstructivepulmonary disease patients. Curr Opin Pulm Med. 2011;17:79-83.

4. Marin JM, Soriano JB, Carrizo SJ, Boldova A, Celli BR. Outcomes in patients with chronic obstructive pulmonary disease and obstructivesleep apne. The overlap syndrome. Am J Respir Crit Care Med. 2010;182:325-331.

5. Cooper CB, Storer TW. Exercise testing and interpretation: a practical approach. London: Cambridge University Press; 2001.

6. American Thoracic Society; American College of Chest Physicians. ATS/ACCP Statement on cardiopulmonary exercise testing. Am J Respir Crit Care Med 2003;167:211-77

7. Gallagher CG, Younes M. Breathing pattern during and after maximal exercise in patients with chronic obstructive lung disease, interstitial lung disease, and cardiac disease, and in normal subjects. Am Rev Respir Dis 1986;133:581-6.

8. Belman MJ, Brooks LR, Ross DJ, Mohsenifar Z. Variability of breathlessness measurement in patients with chronic obstructive pulmonary disease. Chest 1991;99: 566-71.

9. O’Donnell DE, D'Arsigny C, Webb KA. Effects of hyperoxia on ventilatory limitation during exercise in advanced chronic obstructive pulmonary disease. Am J Respir Crit Care Med 2001;163:892-8.

10. O’Donnell DE, D’Arsigny C, Fitzpatrick M, Webb KA. Exercise hypercapnia in advanced chronic obstructive pulmonary disease. Am J Respir Crit Care Med 2002;166:663-8.

11. Efremidis G, Tsiamita M, Manolis A, Spiropoulos K. Accuracy of pulmonary function tests in predicted exercise capacity in COPD patients. Respir Med 2005;99:609-14.

12. Ulubay G, Eyüboğlu Öner F, Şimşek A, Yılmaz İ. Cardiopulmonary exercise testing in the early diagnosis of COPD. Turk Respir J 2006; 7:39-42.

13. O’Donnell. Ventilatory limitations in chronic obstructive pulmonary disease Medicine \& Science in Sports \& Exercise; 2001: 647-55.

14. Peppard P.E.,Young T. Exercise and sleep-disordered breathing: an association independent of body habitus. Sleep 2004; 27: 480-484.

15. Ching-Chi Lin, Wen-Yeh Hsieh, Chon-Shin Chou, Shwu-Fang Liaw. Cardiopulmonary exercise testing in obstructive sleep apnea syndrome. Respiratory Physiology \& Neurobiology 2006;150: 27-34. 